\title{
Copper-catalyzed Regioselective hydroboration of terminal alkynes in aqueous medium
}

Zi-Jian Yao,* Shibin Hong, Wei Zhang, Mengyan Liu and Wei Deng*

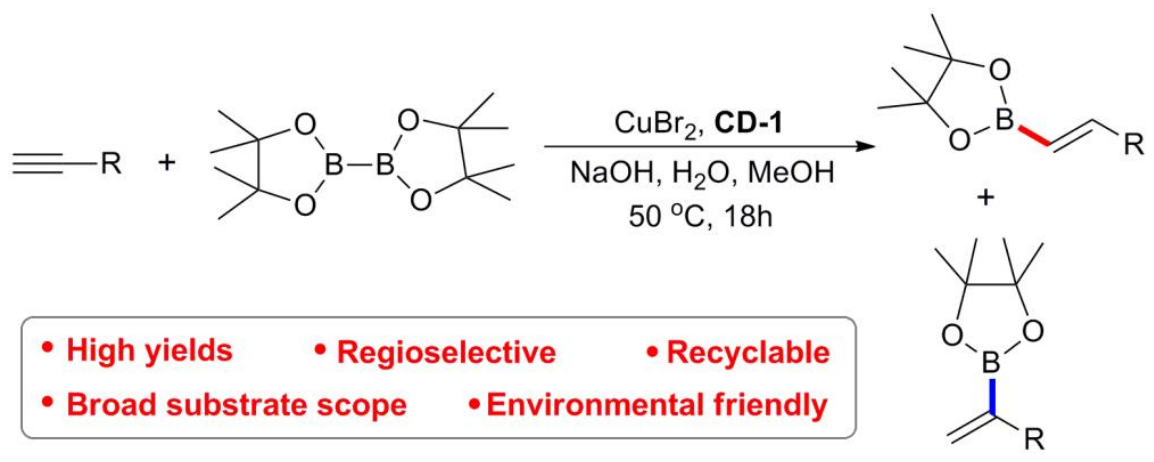

A mild and environment-friendly strategy of copper-catalyzed regioselective hydroboration of terminal alkynes in aqueous medium was developed. 


\title{
Copper-catalyzed regioselective hydroboration of terminal alkynes in aqueous medium
}

\author{
Zi-Jian Yao, ${ }^{\text {a }}$ Shibin Hong, ${ }^{\mathrm{a}}$ Wei Zhang, ${ }^{\mathrm{a}}$ Mengyan Liu ${ }^{\mathrm{a}}$ and Wei Deng**a \\ ${ }^{a}$ School of Chemical and Environmental Engineering, Shanghai Institute of Technology, Shanghai, \\ 201418, P. R. China. E-mail: zjyao@sit.edu.cn; wdeng@shu.edu.cn; Tel: +86-21-60877231; Fax: \\ $+86-21-60873335$ \\ b Nano-Science \& Technology Research Center, Shanghai University, Shanghai, 200444, P. R. \\ China.
}

\begin{abstract}
A mild and environment-friendly copper-catalyzed hydroboration of terminal alkynes in aqueous medium was reported. Regioselectivity control was achieved in the presence of cyclodextrin-bispyridine ligand (CD-1). This protocol was successfully applied to inactivated terminal alkynes. Moreover, the ligand was recovered and reused without any loss of activity over five cycles.
\end{abstract}


Cyclodextrin (CD) is a type of extensively used host molecule competent of guest molecules in aqueous phase. They are often utilized as catalysts in water because of the capacity to dissolve the hydrophobic compounds and the capability to identify diverse molecules. ${ }^{1}$ Among a number of CD derivatives, $\beta$-CD has been broadly used as homogeneous catalysts in various organic reactions. In our previous work, a series of modified CDs for the construction of diverse supramolecular systems have been synthesized. ${ }^{2}$

The C-B bond formation has drawn substantial attention in recent years. ${ }^{3}$ Among largely reported methodologies, copper-catalyzed hydroboration reaction is particularly important, ${ }^{4}$ because unsaturated substrates and diborons $\left(\mathrm{B}_{2} \mathrm{pin}_{2}\right)$ both involved in this catalytic process. Recently, a useful copper-catalyzed borylation has been reported by our group for the preparation of organborons. ${ }^{5}$ However, the untilzation of terminal and $\alpha$-vinyl(pinacolato)borons as substrates in this reaction is still limited, and the current methods involve relatively complex requirements.

Hoveyda $^{6}$ discovered that terminal alkynes could undergo a highly-selective borylation with $\mathrm{B}_{2} \mathrm{pin}_{2}$ in the presence of NHC-Cu catalyst (Scheme 1A). Carretero ${ }^{7}$ also have reported a borylation strategy which relied on the use of a propargylic 2- $\mathrm{PySO}_{2}$ group as an efficient region-director (Scheme 1B). However, high regioselectivity was obtained only when the substrates with propargyl amine, propargyl alcohol or propargylic 2- $\mathrm{PySO}_{2}$ group were employed in this strategy. A highly regioselective hydroboration was reported by Yoshida very recently, and their work represented the first example of $\alpha$-hydroboration by combination of $\mathrm{NHC}-\mathrm{Cu}$ catalyst and a masked diboron substrate (Scheme 1C). ${ }^{3 \mathrm{k}}$ A number of branched borylalkenes were synthesized by this facile and efficient method. Herein, a copper-catalyzed hydroboration of alkynes in aqueous medium is reported. (Scheme 1D). This approach is the first report of regioselective hydroboration of alkynes regiocontrolled by cyclodextrin (CD) derivative and it enables the efficient access to obtain vinyl 
boronates from simple terminal alkynes.

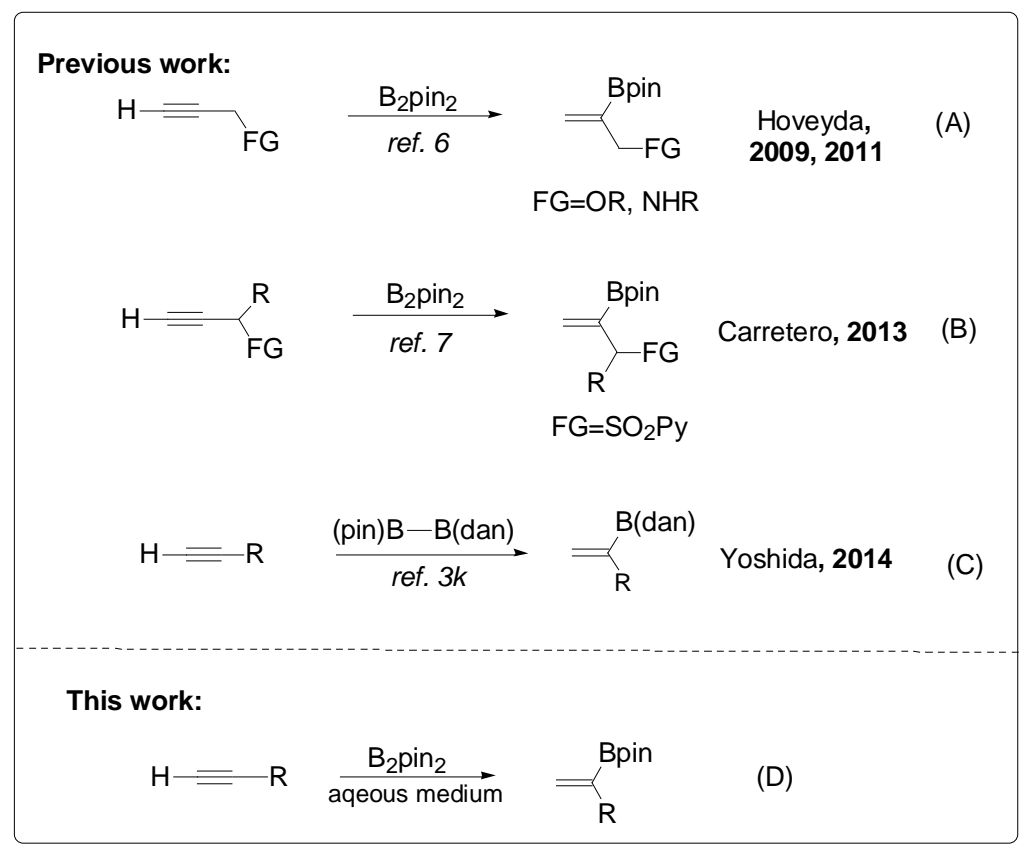

Scheme 1 Regiocontrolled borylation of terminal alkynes.

The cyclodextrin-bispyridine (CD-1) ligand was prepared in almost quantitative yield by click reaction of azide-substituted cyclodextrin $\mathrm{N}_{3}-\beta-\mathrm{CD}$ with $\mathbf{L} \mathbf{1}$ in $1: 1$ molar ratio. The characteristic peaks of triazole ring were observed in the ${ }^{1} \mathrm{H}$ NMR and ${ }^{13} \mathrm{C}$ NMR (See in supporting information). All experiment data revealed that the triazole moiety was bounded to the $\beta-\mathrm{CD}$ unit.

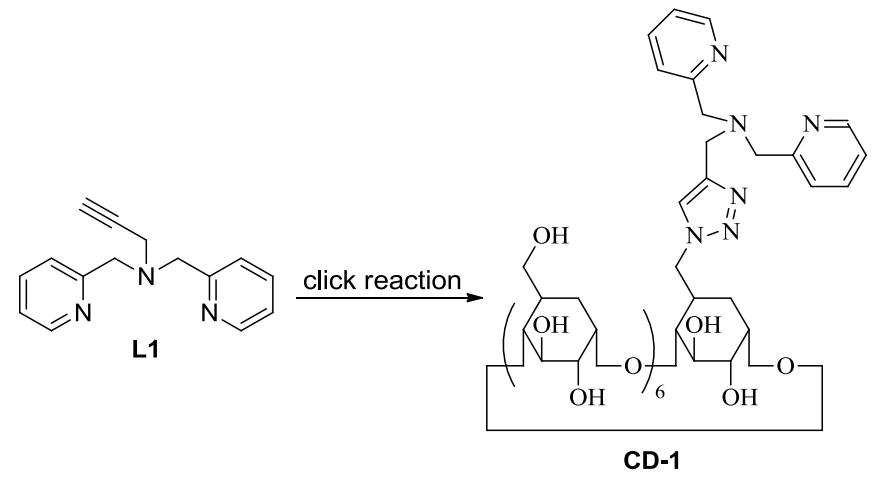

Scheme 2 Synthesis of CD-1

The coupling reaction between 6-chloro-1-hexyne $\mathbf{1 a}$ and $\mathrm{B}_{2} \mathrm{pin}_{2}$ catalyzed by $\mathrm{LiO}^{\mathrm{t}}-\mathrm{Bu}$ in the mixture of toluene and $\mathrm{MeOH}$ was investigated (Table 1, entry 1). Unfortunately the reaction in water using organic base DBU and catalyst CD-1 did not afford any product (Table 1, entries 2 and 
Table 1 Optimization of the reaction ${ }^{\mathrm{a}}$

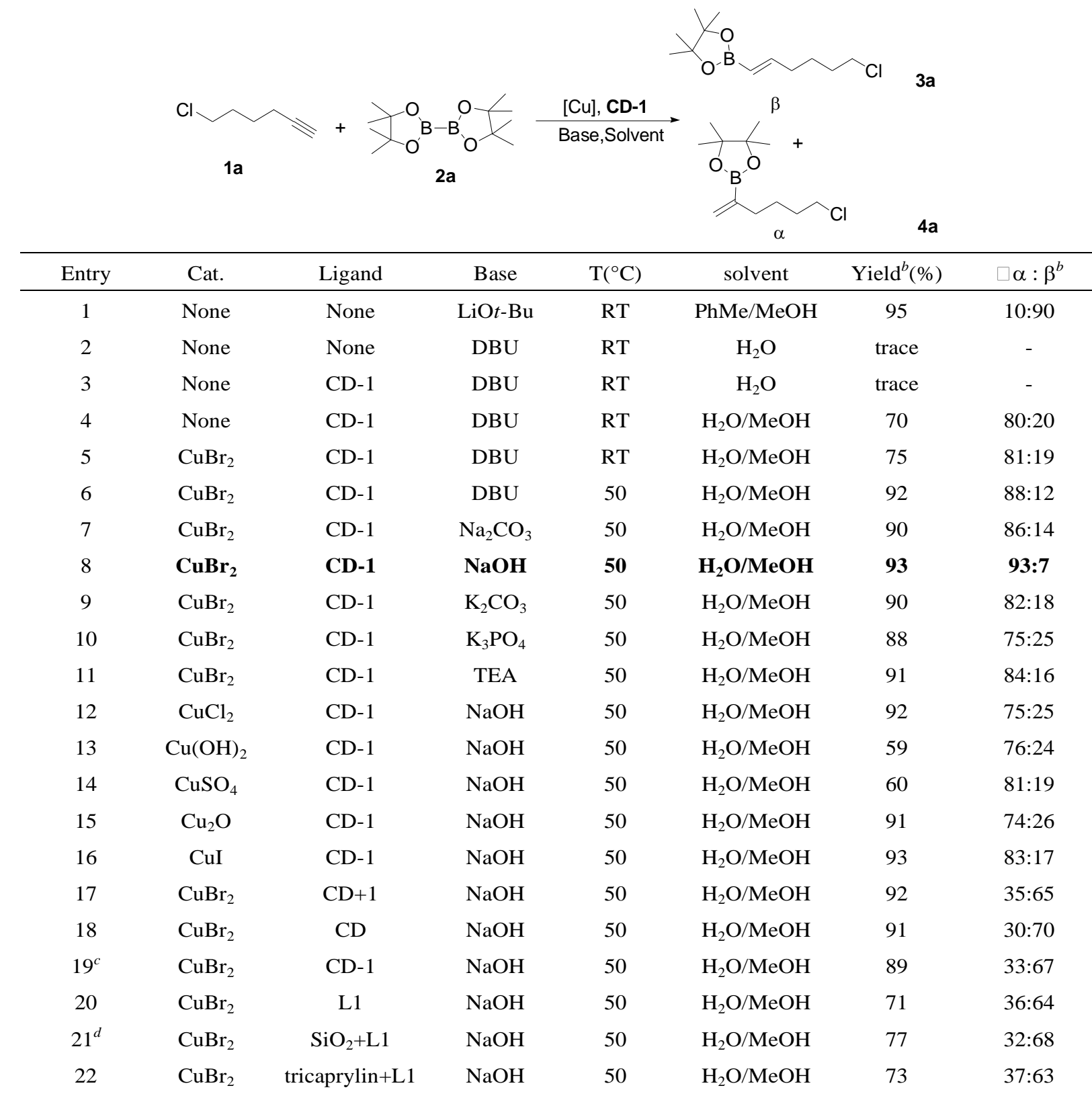

${ }^{a}$ Reactions were carried out using $0.5 \mathrm{mmol}$ 6-chloro-1-hexyne, 1.5 equivalent of $\mathrm{B}_{2} \mathrm{pin}_{2}, 10 \mathrm{mmol} \%$ catalysts and ligands, 2.0 equivalent bases in $2.0 \mathrm{~mL}$ of solvent $\left(\mathrm{H}_{2} \mathrm{O}: \mathrm{MeOH}=1: 1\right)$ was stirred at $50{ }^{\circ} \mathrm{C}$ for $18 \mathrm{~h} .{ }^{b}$ Conversion yield of 1a. Detected by GCMS, pyrene as internal standard. ${ }^{c}$ AdNa was used as additive. ${ }^{d}$ Silica gel (200-300 mesh).

3). The conversion of 1a was slightly improved and the product with moderate regioselectivity ( $\alpha$ : $\beta=80: 20$ ) was obtained when $\mathrm{MeOH}$ was added (Table 1 , entry 4). It was delight to observe that the conversion (92\%) and the regioselectivity $(\alpha: \beta=88: 12)$ both increased when the reaction was catalyzed by $\mathrm{CuBr}_{2}$ at elevated temperature (Table 1, entries 5 and 6). We then optimized the reaction conditions by examining different bases and found that $\mathrm{NaOH}$ was the best choice (Table 1 , 
entries 7-11). Various copper catalysts were screened in the reaction, and the results revealed that most of them $\left(\mathrm{CuCl}_{2}, \mathrm{Cu}_{2} \mathrm{O}, \mathrm{CuI}\right)$, with the exception of $\mathrm{Cu}(\mathrm{OH})_{2}$ and $\mathrm{CuSO}_{4}$, could successfully promote the catalytic process (Table 1, entries 12-16). The regioselectivity decreased obviously when the reaction was catalyzed by $\mathrm{CuBr}_{2}$ in the presence of $\mathrm{CD}$ or the mixture of $\mathrm{CD}$ and $\mathbf{L 1}$ (Table 1, entries 17 and 18). In comparison with the result of entry 18, the addition of AdNa has little influence on regioselectivity (Table 1, entry 19). The control experiment of eliminating CD was also performed. Moderate yields and low regioselectivity was obtained when the reaction was performed in the presence of $\mathrm{CuBr}_{2}$ and $\mathbf{L 1}$ (Table 1, entry 20). Other additives such as $\mathrm{SiO}_{2}$ and tricaprylin, which can provide hydrophobic environment in aqueous medium, were also used in the reaction (Table 1, entries 21 and 22). All results suggested that CD play a key role in the reaction.

With optimized reaction conditions in hand $\left(\mathrm{CuBr}_{2} / \mathrm{CD}-1 / \mathrm{NaOH}\right.$ catalytic system), the hydroboration of various terminal alkynes was examined. As shown in Table 2, most of the reactions gave products with good yields and high regioselectivity. The reactions of linear alkylalkynes afforded the $\alpha$-vinyl(pinacolato)borons in good to excellent yields (70 \%-93 \%) (1a-g), but high regioselectivity was only obtained (93:7) from alkynes with six carbons (1a, 1g). The steric effects played an important role when alkyl-substituted alkynes were used as substrates in the reaction. Moderate yields ( $70 \%)$ and regioselectivity ( 60:40) were obtained in most cases (1h, $\mathbf{1 j}$, 1k), high yield (up to $90 \%$ ) was only observed when cyclopropylacetylene (1i) was employed in the reaction. The reactivity of aryl alkynes was also investigated. The results reveal that the carbon chain between the aryl functional group and alkynyl group is shorter, the regioselectivity is higher (11 and 1m). The regioselectivity is not good when the alkynes containing the substituted groups with heteroatoms (1n-p).

The reactivity of aryl terminal alkynes was also investigated under the optimized conditions 
(Table 2). The reactions of arylalkynes gave worse regioselectivities than those of alkylalkynes, possibly due to the steric hindrance. The reaction between phenylacetylene and diborane afforded the corresponding product in $69 \%$ yield with low regioselectivity (1q). A wide range of para-substituted aryl terminal alkynes were tested, reactions of $\mathbf{1 r}-\mathbf{1} \mathbf{u}$ with diborane led to analogous products with similar yields and regioselectivities. There was no improvement on regioselectivity when the ortho and meta-substituted arylalkynes were utilized in the reaction $(\mathbf{1 v}-\mathbf{x})$.

Table 2 Scope of alkynes.
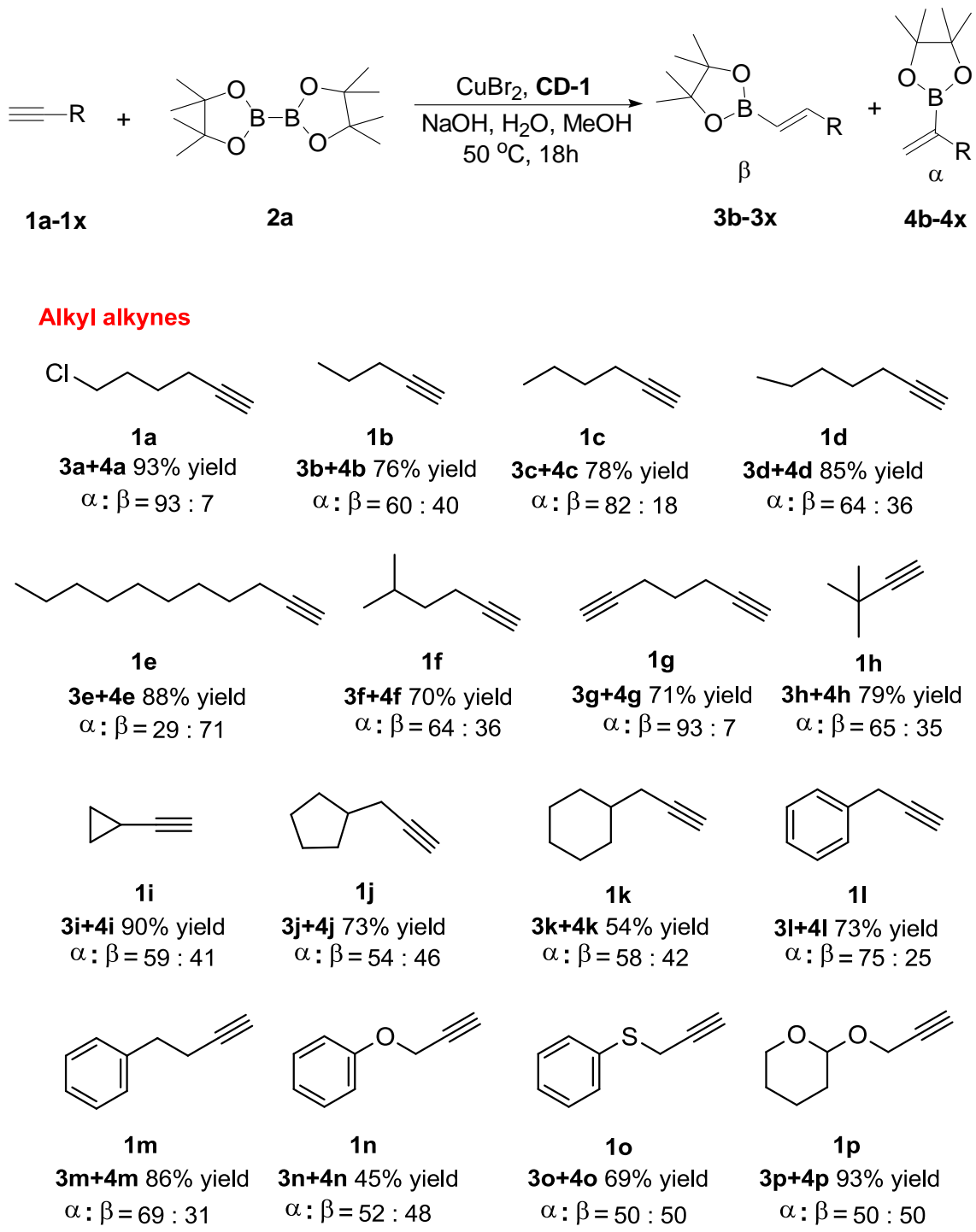


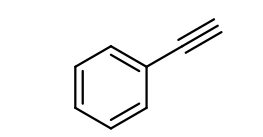

$1 q$

$3 q+4 q 69 \%$ yield

$\alpha: \beta=19: 81$

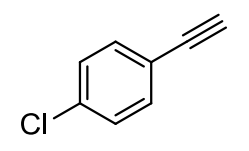

$1 \mathrm{u}$

$3 u+4 u+79 \%$ yield

$\alpha: \beta=14: 86$

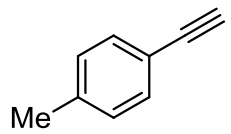

$1 \mathrm{r}$

$3 \mathbf{r}+\mathbf{4 r} \mathbf{7 0} \%$ yield

$\alpha: \beta=14: 86$

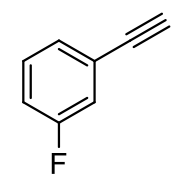

$1 v$

$3 v+4 v 84 \%$ yield

$\alpha: \beta=8: 92$

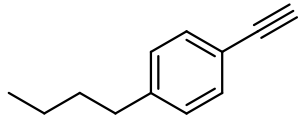

$1 \mathrm{~s}$

$3 s+4 s$ 95\% yield

$\alpha: \beta=20: 80$

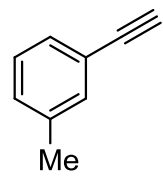

$1 w$

$3 \mathbf{w}+\mathbf{4} \mathbf{w} 63 \%$ yield

$\alpha: \beta=28: 72$

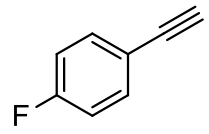

$1 \mathbf{t}$

$\mathbf{3 t}+\mathbf{4 t} \mathbf{8 7 \%}$ yield

$\alpha: \beta=14: 86$<smiles>C#Cc1ccccc1Cl</smiles>

$1 \mathrm{x}$
$3 \mathrm{x}+4 \mathrm{x}$
$55 \%$ yield

$\alpha: \beta=29: 71$

Encouraged by the results achieved above, we turned our attention to the reuse of the ligand (CD-1) in hydroboration of alkynes (Table 3). The use of cyclodextrin ligand made it easy to separate the product from the reaction mixture by simple extraction. To our delight, the ligand can be reused for at least fifth cycles without any loss of activity, which is an obligatory for its practical application.

Table 3 Reuse of the ligand CD-1 for the hydroboration of 6-chloro-1-hexyne.

\begin{tabular}{lccccc}
\hline Cycle times & 1 & 2 & 3 & 4 & 5 \\
Yield (\%) & 93 & 92 & 90 & 90 & 91 \\
${ }^{a}$ Reactions condition: Optimized condition.
\end{tabular}

In summary, a highly efficient and regioselective method for alkyne hydroboration in aqueous medium has been developed. This method provides easy access to a library of borylation compounds from readily available starting materials. The environment-friendly reaction condition and the reusable feature of the ligand make this catalytic system very attractive in industrial applications. 


\section{Acknowledgement}

This work was supported by the Eastern Scholar, Key Subject of Shanghai Municipal Education Commission, Shanghai Municipal Education Commission (Plateau Discipline Construction Program), National Science Foundation of China (No. 21102088 and 21174081), and start funding of Shanghai Institute of Technology.

\section{Notes and references}

1 (a) Hu, S.; Li, J.; Xiang, J.; Pan, J.; Luo, S.; and Cheng, J.-P. J. Am. Chem. Soc. 2010, 132, 7216-7228; (b) Takashima, Y.; Uramatsu, K.; Jomori, D.; Harima, A.; Otsubo, M.; Yamaguchi, H.; and Harada, A. ACS Macro. Letters 2013, 2, 384-387; (c) Zhang, G.; Luan, Y.; Han, X.; Wang, Y.; Wen, X.; Ding, C.; and Gao, J. Green Chem. 2013, 15, 2081-2085; (d) Kaboudin, B.; Mostafalu, R.; and Yokomatsu, T. Green Chem. 2013, 15, 2266-2274; (e) Jérôme, F.; Ferreira, M.; Bricout, H.; Menuel, S.; Monflier, E.; and Tilloy, S. Green Chem. 2014, 16, 3876-3880; (f) Guitet, M.; Marcelo, F.; de Beaumais, S. A.; Zhang, Y.; Jiménez-Barbero, J.; Tilloy, S.; Monflier, E.; Ménand, M.; and Sollogoub, M. Eur. J. Org. Chem. 2013, 18, 3691-3699; (g) Li, Z. -Q.; Zhang, Y. -M.; Chen, Y.; and Liu, Y. Chem. Eur. J. 2014, 20, 8566-8570; (h) Kanagaraj, K.; and Pitchumani, K. Chem. Eur. J. 2013, 19, 14425-14431; (i) Li, N.; Zhao, P.; Liu, N.; Echeverria, M.; Moya, S.; Salmon, L.; Ruiz, J.; and Astruc, D. Chem. Eur. J. 2014, 20, 8363-8369; (j) Tran, D. N.; Legrand, F.-X.; Menuel, S.; Bricout, H.; Tilloy, S.; and Monflier, E. Chem. Commun. 2012, 48, 753-755; (k) 
Blaszkiewicz, C.; Bricout, H.; Leonard, E.; Len, C.; Landy, D.; Cezard, C.; Djedaini-Pilard, F.; Monflier, E.; and Tilloy, S. Chem. Commun. 2013, 49, 6989-6991; (1) Guitet, M.; Zhang, P.; Marcelo, F.; Tugny, C.; Jiménez-Barbero, J.; Buriez, O.; Amatore, C.; Mouriès-Mansuy, V.; Goddard, J.-P.; Fensterbank, L.; Zhang, Y.; Roland, S.; Ménand, M.; and Sollogoub, M. Angew. Chem. Int. Ed. 2013, 52, 7213-7218; (m) Léger, B.; Menuel, S.; Ponchel, A.; Hapiot, F.; and Monflier, E. Adv. Synth. Catal. 2012, 354, 1269-1272; (n) Yang, Z.; and Ji, H. ACS Sustainable Chemistry \& Engineering 2013, 1, 1172-1179; (o) Kairouz, V.; and Schmitzer, A. R. Green Chem. 2014, 16, 3117-3124; (p) Calcio Gaudino, E.; Carnaroglio, D.; Martina, K.; Palmisano, G.; Penoni, A.; and Cravotto, G. Org. Process Res. Dev. 2015, 19, 499-505; (q) Zhao, X.; Liu, X.; Lu, M. Appl. Organomet. Chem. 2014, 28, 635-640; (r) Wu, J.; Du, X.; Ma, J.; Zhang, Y.; Shi, Q.; Luo, L.; Song, B.; Yang, S.; and Hu, D. Green Chem. 2014, 16, 3210-3217.

2 (a) Hong, S.; Liu, M.; Shuai, Y.; Wang, Z.; Shi, L.; and Deng, W. J. Incl. Phenom. Macrocycl. Chem. 2014, 80, 443-448; (b) Kulkarni, A.; Deng, W.; Hyun, S.-h.; and Thompson, D. H. Bioconjug. Chem. 2012, 23, 933-940; (c) Deng, W.; Chen, J.; Kulkarni, A.; and Thompson, D. H. Soft Matter 2012, 8, 5843-5846; (d) Deng, W.; Thompson, D. H. Soft Matter 2010, 6, 1884-1887; (e) Deng, W.; Yamaguchi, H.; Takashima, Y.; Harada, A. Chem. Asian J. 2008, 3, 687-695; (f) Deng, W.; Yamaguchi, H.; Takashima, Y.; Harada, A. Angew. Chem. Int. Ed. 2007, 46, 5144-5147; (g) Deng, W.; Onji, T.; Yamaguchi, H.; Ikeda, N.; Harada, A. Chem. Commun. 2006, 4212-4214.

3 (a) Semba, K.; Bessho, N.; Fujihara, T.; Terao, J.; Tsuji, Y. Angew. Chem. Int. Ed. 2014, 53, 9007-9011; (b) Qiu, D.; Zhang, Y.; Wang, J. Org. Chem. Front. 2014, 1, 422-425; (c) Mlynarski, S. N.; Schuster, C. H.; Morken, J. P. Nature 2014, 505, 386-390; (d) Luo, Y.; 
Roy, I. D.; Madec, A. G. E.; Lam, H. W. Angew. Chem. Int. Ed. 2014, 53, 4186-4190; (e)

Kitanosono, T.; Xu, P.; Isshiki, S.; Zhu, L.; Kobayashi, S. Chem. Commun. 2014, 50, 9336-9339; (f) Hong, K.; Liu, X.; Morken, J. P.; J. Am. Chem. Soc. 2014, 136, 10581-10584; (g) Cho, S. H.; Hartwig, J. F. Chem. Sci. 2014, 5, 694-698; (h) Bose, S. K.; Fucke, K.; Liu, L.; Steel, P. G.; Marder, T. B. Angew. Chem. Int. Ed. 2014, 53, 1799-1803; (i) Blaisdell, T. P.; Caya, T. C.; Zhang, L.; Sanz-Marco, A.; Morken, J. P. J. Am. Chem. Soc. 2014, 136, 9264-9267; (j) Lee, J. -E.; Kwon, J.; Yun, J. Chem. Commun. 2008, 733-734; (k) Yoshida, H.; Takemoto, Y.; Takaki, K. Chem. Commun. 2014, 50, 8299-8302; (1) Yao, Z. -J.; Yu, W. -B.; Huang, S. -L.; Lin, Y. -J.; Li, Z. -H.; Jin, G. -X. J. Am. Chem. Soc. 2014, 136, 2825-2833; (m) Yao, Z. -J.; Deng, W. Coord. Chem. Rev. 2016, 309, 21-35; (n) Yao, Z. -J.; Jin, G. -X. Coord. Chem. Rev. 2013, 257, 2522-2535.

4 (a) Tan, X.-H.; Shen, B.; Deng, W.; Zhao, H.; Liu, L.; Guo, Q.-X. Org. Lett. 2003, 5, 1833-1835; (b) Deng, W.; Wang, Y.-F.; Zou, Y.; Liu, L.; Guo, Q.-X. Tetrahedron Lett. 2004, 45, 2311-2315; (c) Deng, W.; Liu, L.; Zhang, C.; Liu, M.; Guo, Q.-X. Tetrahedron Lett. 2005, 46, 7295-7298; (d) Wang, J.-R.; Liu, L.; Wang, Y.-F.; Zhang, Y.; Deng, W.; Guo, Q.-X. Tetrahedron Lett. 2005, 46, 4647-4651.

5 (a) Liu, M.-Y.; Hong, S.-B.; Zhang, W.; Deng, W. Chin. Chem. Lett. 2015, 26, 373-376; (b) Hong, S.; Liu, M.; Zhang, W.; Zeng, Q.; Deng, W. Tetrahedron Lett. 2015, 56, 2297-2302.

6 (a) Lee, Y.; Jang, H.; Hoveyda, A. H. J. Am. Chem. Soc. 2009, 131, 18234-18235; (b) Jang, H.; Zhugralin, A. R.; Lee, Y.; Hoveyda, A. H. J. Am. Chem. Soc. 2011, 133, 7859-7871.

7 Moure, A. L.; Mauleón, P.; Arrayás, R. G.; Carretero, J. C. Org. Lett. 2013, 15, 2054-2057. 